University of Nebraska - Lincoln

DigitalCommons@University of Nebraska - Lincoln

Sociology Department, Faculty Publications

Sociology, Department of

$7-2010$

Birth weight, cognitive development, and life chances: A comparison of siblings from childhood into early adulthood

Jacob Cheadle

University of Nebraska-Lincoln, jcheadle2@unl.edu

Bridget J. Goosby

University of Nebraska-Lincoln, bgoosby2@unl.edu

Follow this and additional works at: https://digitalcommons.unl.edu/sociologyfacpub

Part of the Sociology Commons

Cheadle, Jacob and Goosby, Bridget J., "Birth weight, cognitive development, and life chances: A comparison of siblings from childhood into early adulthood" (2010). Sociology Department, Faculty Publications. 164.

https://digitalcommons.unl.edu/sociologyfacpub/164

This Article is brought to you for free and open access by the Sociology, Department of at DigitalCommons@University of Nebraska - Lincoln. It has been accepted for inclusion in Sociology Department, Faculty Publications by an authorized administrator of DigitalCommons@University of Nebraska - Lincoln. 
Published in Social Science Research 39:4 (July 2010), pp. 570-584; doi: 10.1016/j.ssresearch.2010.03.003

Copyright $(\subset) 2010$ J. Cheadle and B. Goosby. Published by Elsevier Inc. Used by permission.

Published online March 15, 2010.

This research was partially supported by small grant from the National Poverty Center at the University of Michigan. All opinions and errors are the sole responsibility of the authors and do not necessarily reflect those of either the helpful commentators or funding agencies.

\title{
Birth weight, cognitive development, and life chances: A comparison of siblings from childhood into early adulthood
}

\author{
Jacob E. Cheadle ${ }^{1}$ and Bridget J. Goosby ${ }^{2}$ \\ 1. University of Nebraska-Lincoln, 737 Oldfather Hall, Lincoln, NE 68588-0324, USA; email j.e.cheadle@gmail.com \\ 2. University of Nebraska-Lincoln, 741 Oldfather Hall, Lincoln, NE 68588-0324, USA; email bgoosby@gmail.com \\ Corresponding author - J. E. Cheadle
}

\begin{abstract}
Using data from the National Longitudinal Survey of Youth Child Sample (CNLSY79), we sought to elaborate the complex interplay between childhood health and educational development over the early life course. Our approach made use of sibling comparisons to estimate the relationship between birth weight, cognitive development, and timely high school completion in models that spanned childhood, adolescence, and into early adulthood. Our findings indicated that lower birth weight, even after adjusting for fixed-family characteristics and aspects of the home environment that varied between siblings, was associated with decreased cognitive skills at age 5 and marginally significantly slower growth rates into adolescence. In addition, low birth weight increased the risk of not graduating by age 19, although this relationship reflected differences in cognitive development. Additional moderation analyses provided no evidence that birth weight effects are exacerbated by social conditions. Overall, the pattern of findings painted a complex picture of disadvantage, beginning in the womb and presumably via educational attainment, extending over the life course.
\end{abstract}

Keywords: childhood health, birth weight, cognitive development, attainment

\section{Introduction}

There is growing interest among social scientists in the role childhood health plays in social stratification processes over the life course (Strully and Conley, 2004; Link and Phelan, 1995). One reason for this attention is an increasing recognition that early life social and physical conditions decrease educational attainments (Conley et al., 2003) which results in health and mortality differentials in the later years (Hayward and Gorman, 2004). Research explicitly linking health to achievement and developmental processes across childhood, adolescence, and into adulthood is relatively rare, however (e.g., Hayward et al., 2000). Prior examples in the literature linking childhood health to socioeconomic attainment processes have been based on cross-sectional analysis (e.g., Gorman, 2002a, 2002b), growth models of cognitive development (e.g., Goosby and Cheadle, 2009; Boardman et al., 2002), or models of attainment which sometimes make use of prior achievement scores (e.g., Haas and Fosse, 2008). These studies, however, do not incorporate explicit models of development and attainment into a single framework.

Although childhood health as measured by birth weight has been linked to achievement (Goosby and Cheadle, 2009; Boardman et al., 2002) and timely high school completion (Conley and Bennett, 2000, 2001; Haas and Fosse, 2008), not all studies support these findings (e.g., Gorman, 2002a, 2002b), indicating that important questions about the nature and 
magnitude of birth weight effects remain. Moreover, a unified model assessing whether the impact of birth weight on attainment operates directly through cognitive development or whether effects are independent has, to our knowledge, yet to be undertaken. Thus, the extent and nature of birth weight influences on cognitive development and indicators of attainment, like high school completion, have yet to be fully demonstrated. This study attempts to provide such a model by incorporating longitudinal growth models of youth cognitive developmental trajectories as birth weight mediators into models of high school completion.

Using sibling data from the Children of the National Longitudinal Survey of Youth (CNLSY79) we address the following questions: (1) Is birth weight related to cognitive development in childhood and (2) are there birth weight differences in cognitive growth into adolescence? (3) Is birth weight associated with timely high school completion and (4) is the relationship between birth weight and high school completion accounted for by cognitive development? Previous research indicates that birth weight and social conditions, such as income and family context, are correlated with each other and with subsequent achievement into adulthood. Birth weight effect estimates will be biased when factors which cause low birth weight, decrease cognitive performance, and lower educational attainment are omitted from statistical models. Because controlling for these common causes is difficult, it is unclear whether birth weight or social conditions are the real causes of differences in outcomes (see, for example, Conley et al., 2003; Royer, 2006; Behrman and Rosenzweig, 2004). Accordingly, we make use of sibling-comparison models to adjust for temporally invariant omitted factors (e.g., Guo and VanWey, 1999), along with measures of the family context that vary between siblings, leading to our final question: (5) Do birth weight associations persist when controlling for confounding factors that are constant within-families or vary between siblings in the same families?

\section{Background}

\subsection{Birth weight, child development, and educational attainment}

Although there is evidence that birth weight is associated with a range of developmental outcomes (see Hack et al., 1995 for a review), the mechanisms by which birth weight results in decreased achievement and life chances are not entirely clear. Children born premature and LBW (hereafter LBW; births $<2500 \mathrm{~g}$ ) can have immature lungs leading to birth asphyxia ${ }^{1}$ and other complications (e.g., severe periventricular hemorrhage) which can, in turn, result in severe trauma for the smallest babies (Hack et al., 1995). The "fetal origins" or "Barker hypothesis," which has been advocated as an explanation for a number of adult-onset chronic diseases, suggests that the factors causing LBW may also increase risk for developmental impediments (see Barker, 1995; Barker et al., 1993; Godfrey and Barker, 2001). Specifically, children born LBW, are at risk for numerous health and developmental problems including growth retardation, physical illness though adulthood, and mental health problems (Breslau, 1995; Hack et al., 1995; McCormick et al., 1992). Moreover, LBW children are at risk for lower reading and math score growth (Goosby and Cheadle, 2009; Boardman et al., 2002), lower IQ scores (Hack et al., 2002), school problems (McCormick et al., 1990; Klebanov et al., 1994a, 1994b), grade failure and placement in special classes (Klebanov et al., 1994a, 1994b), and decreased likelihood of timely high school completion (Conley et al., 2003).

Social factors appear to play an important role in infant health (e.g., Hughes and Simpson, 1995; Paneth, 1995) indicating that some developmental birth weight consequences result from social factors which are not always adequately measured and accounted for in statistical analyses. Moreover, children from different social classes and racial/ethnic backgrounds are not at equal risk for LBW with those facing the most detrimental social conditions also being more likely to be born prematurely and/or of lower birth weight (Paneth, 1995; Cramer, 1995; Sastry and Hussey, 2003). Gaps in birth weight among social, economic, racial/ethnic groups, and geographic areas have not substantially lessened in recent years despite increased medical care expenditures (Pearl et al., 2001; Hahn et al., 1995; Pappas et al., 1993; Gortmaker and Wise, 1997), and may in fact have increased as a result of welfare reform (Kaestner and Lee, 2003).

Children who grow up experiencing economic disadvantage are at increased risk for slower cognitive development resulting from resource deficits and less favorable home environments, poor school environments, and physical health problems (Duncan and Brooks-Gunn, 1997). Although not all studies find that birth weight is related to slower intellectual development, particularly Gorman (2002a, 2002b) who used a methodologically strong twin design in an adolescent sample, research generally supports the conclusion that birth weight negatively influences development - both cognitive development and later educational attainment. Furthermore, LBW in the US is an important social problem which does not appear to be lessening with time.

\subsection{The role of family context}

Parents with fewer economic resources are often less likely to effectively parent and invest in children's developmental and academic well-being (McLoyd, 1998). These family circumstances may be due to higher levels of stress and increased risk for mental and physical health problems among the poor, which in turn, contributes to both employment declines

1. Birth asphyxia can occur for a number of other reasons, including maternal low blood oxygen do to respiratory or heart problems, low blood pressure, poor placental function, and other complications. 
(Danzinger et al., 2002) and increased risks for poorer health outcomes among their children (Springer, 2009; Repetti et al., 2002). Prior research addressing social disadvantage and child development emphasizes the importance of resources and parent educational investments in setting children on trajectories leading to less favorable attainments (Mayer, 1997; Guo and Harris, 2000; Farkas and Beron, 2004). Children experiencing financial and other forms of disadvantage enter school with lower educational (Lee and Burkham, 2002; Cheadle, 2008, 2009) and cognitive skills than their more advantaged counterparts (Smith et al., 1997; Mayer, 1997). At least part of the influence of birth weight on development and high school completion may be a result of these factors.

Lower socioeconomic status is correlated with LBW, which can have far reaching effects on later educational outcomes (Conley and Bennett, 2000; Hack et al., 1995; Reichman, 2005). There is evidence that LBW is significantly associated with fewer expressed learning behaviors in early childhood (Morgan et al., 2009) and lower test scores in early (Hillemeier et al., 2009) and middle childhood (Boardman et al., 2002), especially for children who are considered VLBW ( $<1500$ g; Hack et al., 1995). Adjustment for social correlates, however, appears to reduce birth weight gradients (Goosby and Cheadle, 2009), indicating that at least part of the observed associations between birth weight and achievement results from social conditions correlated with the proximate LBW causes.

Parents with greater access to economic and educational resources are more likely to provide their children with improved schooling environments, choose to send their children to better schools, live in safer neighborhoods, and have access to health care they may not otherwise be able to afford (Lareau, 2003; Gottfried et al., 2003). Additionally, parents with more resources are also able to accommodate their children's educational "styles" or predilections, allowing them to self-select the materials they find the most engaging (Guo and Harris, 2000). While providing these amenities for their children, they also have the time and ability to invest more in their children (e.g., Lareau, 2003; Cheadle, 2008, 2009; Chin and Phillips, 2004), which suggests that family circumstances may "buffer" the negative effects of birth weight on educational outcomes.

Although the data suggesting that birth weight is moderated by family circumstances is sparse (e.g., Lin et al., 2007; Conley and Bennett, 2001; Currie and Hyson, 1999; Hack et al., 1995), research with large samples and sufficient statistical power are relatively rare in birth weight moderation studies. Conley and colleagues (2007), using the PSID-CDS, for example, report that birth weight is related to achievement for black siblings and siblings with a mother with less than a high school education. As Conley and Bennett (2001, p. 451) note, understanding the interactions between birth weight and family circumstances is "potentially of great import from a policy perspective... [T] he additional knowledge gained allows us to focus more precisely on those families at high risk and thus greater efficiency in the efforts to address low birth weight and its harmful consequences."

\subsection{The study design}

Our research design is based upon four primary features which make the analysis stronger than most existing studies. First, the dynamics of development are captured in a longitudinal analysis of growth and change in cognitive development. The parameters for the change trajectories are then used as independent variables along with birth weight to predict timely high school completion in a unified developmental model spanning from childhood into early adulthood. Second, our models of cognitive growth are based on free-factor loading models which allow average growth to be estimated nonparametrically.

Third, the developmental trajectories are estimated within the context of a sibling-comparison model, which is a random effects model incorporating the shared social and genetic environments of siblings in the same family (Conley et al., 2003; Behrman and Rosenzweig, 2004; Royer, 2006; Conley and Bennett, 2000, 2001; Gorman, 2002a, 2002b). The random effects at the family level represent unobserved factors that may capture important common causes of birth weight and our outcomes. If not accounted for, these common causes can lead to the well-known problem of omitted variable bias in our birth weight effect estimates (see, e.g., Bollen, 1989, chap. 3). Including the random effects while centering the birth weight and family context variables around their family means controls for these unobserved variables in a fashion similar to econometric fixed-effects methods which include a dummy variable for each family (e.g., Allison, 2005).

Finally, the model of developmental growth allows changes in the social context over time that are not captured by the random effects, including family social contexts that differ across siblings of different ages, to be incorporated into the model. These time-varying sources of variation present important opportunities to study sources of variation in outcomes within-families (Conley et al., 2007). For example, siblings growing up in a family that has changing economic status will experience different family social contexts when comparing younger and older siblings.

\subsection{Our contribution}

Our principal goal in this study is to elaborate the complex interplay between health and cognitive development over the early life course. From a life course perspective, this study contributes to research on the relationship between health and the process of status attainment. In addition, this research contributes to the growing body of work on how health and achievement processes are linked over the life course (Hayward et al., 2000; Hayward and Gorman, 2004). By comparing the achievement trajectories of siblings with different birth weights, and families with different average birth weights, in addition to using the achievement growth trajectories as mediators of the relationship between birth weight and high school completion, we are able to model a long-term developmental sequence spanning childhood to early adulthood the foundational status attainment stages. Because our approach allows us to estimate parameters that produce variation 
between siblings and between-families, coefficients for these between-family models are useful for understanding aspects of social background which are both related to birth weight and educational outcomes. Finally, we explore the extent to which the impact of birth weight on development is moderated by early childhood social conditions with the CNLSY79, a large nationally representative data source with sufficient statistical power to detect important interactions.

\section{Data and methods}

Our analysis uses data from the National Longitudinal Survey of Youth, 1979 (NLSY79) adult cohort and their children in the Child and Young Adult Supplement (CNLSY79). The data, which were collected by The Center for Human Resource Research (CHRR) at Ohio State University, began in 1979 with a sample of approximately 12,600 respondents between the ages of 14 and 21, and included an oversample of African American and low-income families. Biennial assessment of all children of the NLSY79 mothers began in 1986, and included information on child health and background along with responses from children to assessment items and interviewer observations in the child's home environment.

There were a total of 8,835 children out of 11,340 with at least one math and/or reading score (of two reading assessments) available for study. The longitudinal nature of the data, however, resulted in covariate missingness which, after listwise deleting on the exogenous variables, reduced the sample size to 5,947 cases. $^{2}$ We addressed the missing data problem using multiple imputation which assumes that missing values are conditionally missing at random (Little and Rubin, 2002) using the MICE system of chained equations implemented via the Ice routine in Stata (Royston, 2004, 2005a, 2005b). The imputation model that was used to generate the 10 imputation data sets contained all variables included in the analysis, including factor scores of the growth model parameters and factor scores of the combined cognitive development variables, the analysis variables, and the family means.

Before conducting the growth analysis, we restricted the sample size to families with two or more children to ensure that all youth contribute to both the within-family and between-family model components. This restriction resulted in a working sample size of 7,126 cases after imputation. Youth became eligible for the high school completion analysis after turning 19. Prior to imputation, the maximal sample size was 1,629, after imputation the sample size was 3697 for models without the growth parameters. The sample size for models including the growth parameters was 5,280 because these models included siblings who were less than 19 years and who were used to contribute to the precise estimation of the growth parameters. The high school completion parameters were based on the sample of 3,697 young adults because youth less than 19 years contributed information only to the estimation of the growth parameters. The growth models were based on assessments at approximately 5, 8, 10,12, 14 years of age and, as noted above, the high school completion analysis utilized a sample of young adults 19 or older with the siblings $<19$ years contributing only to the estimation of the growth parameters.

\subsection{Dependent variables}

We analyzed two dependent variables. Following Guo and Harris (2000), the first of these viewed cognitive development holistically by using a factor created from the three Peabody Individual Achievement Test (PIAT) assessments: reading recognition (PIATR), reading comprehension, (PIATC) and mathematics (PIATM). The PIATR measured word recognition and pronunciation, the PIATC measured youth's ability to interpret and derive meanings from written materials, and the PIATM assessed children's achievement in the mathematics typically taught in US schools (e.g., recognizing numerals, trigonometry, etc.). The age-specific factor scores used for the growth modeling were calculated by estimating a joint model which allowed measures at additional waves to contribute to the precision of the factor score estimates through correlated age-specific factors (years $5,8,10,12$, and 14). ${ }^{3}$ The standardized factor loadings were all above .73 for the PIATM and .8 for the PIATR and PIATC across factors, which indicated that the factors were weighted slightly toward reading skills. Estimates of Cronbach's a for each age were all at .83 or above. With regards to the multiple imputation model, we first estimated the factor scores and then included the factor scores in the model, imputing for those missing on two or more of the PIAT assessments.

The second dependent variable was high school or GED completion, an important life cycle milestone and one that punctuates the long developmental process, by or after age 19. We constructed an indicator of whether or not the youth of the CNLSY who reached age 19 at or before the 2004 wave of data collection had received a high school diploma or completed a GED $(0=$ completed HS/GED, $1=$ did not $){ }^{4}$

\footnotetext{
2. This sample size also makes certain assumptions about some independent variables in a full-information maximum likelihood estimation routine. Full listwise deletion halves the working sample size yet again.

3. Since the scaling was arbitrary the factor scores were scaled to the PIATR.

4. One potential concern with our coding of this variable stems from the grouping of the high school graduation and GED groups. In order to test whether this assumption was reasonable, we estimated a multinomial logit equation and constructed linear constraints that were the differences in the birth weight piecewise (see the Birth Weight section for the operationalization) coefficients for the high school graduation/no graduation and the GED/no graduation equations. The $F(2,291.4)$ statistic for the joint test for differences in slopes for birth weights below the sample average $(3300 \mathrm{~g})$ was $.32(p$-value $=.73)$. This result, along with separate results for each piece of the birth weight effect, indicated that the effect of birth weight on graduation/GED relative to no graduation were not statistically distinguishable - a finding which justifies our grouping of these categories.
} 
Table 1. Descriptive statistics with the $N$ used for the imputation model, the non-missing $N$, mean, standard deviation, intraclass correlation (ICC), min, and maximum values.

\begin{tabular}{|c|c|c|c|c|c|c|c|}
\hline Variable & $N$ & $\% N$ & Mean & SD & ICC & Min & Max \\
\hline Cognitive development, age 14 & 3650 & 51 & 59.29 & 12.08 & 0.50 & 5 & 91 \\
\hline HOME score, age 5 & 5176 & 73 & -0.03 & 1.02 & 0.58 & -5 & 2 \\
\hline Single mother, age 5 & 5368 & 75 & 0.14 & 0.35 & 0.85 & 0 & 1 \\
\hline Single mother, age 14 & 3660 & 51 & 0.14 & 0.35 & 0.89 & 0 & 1 \\
\hline Divorced mother, age 5 & 5368 & 75 & 0.20 & 0.40 & 0.56 & 0 & 1 \\
\hline Income $(\ln )$, age 14 & 4540 & 64 & 10.14 & 1.06 & 0.51 & 0 & 13 \\
\hline Birth weight & 6574 & 92 & 3298.59 & 596.18 & 0.40 & 822 & 4990 \\
\hline Female & 7126 & 100 & 0.49 & 0.50 & 0.00 & 0 & 1 \\
\hline Black & 7126 & 100 & 0.32 & 0.47 & - & 0 & 1 \\
\hline Hispanic & 7126 & 100 & 0.21 & 0.41 & - & 0 & 1 \\
\hline Mother's AFQT & 6830 & 96 & -0.02 & 1.00 & - & -1 & 2 \\
\hline HOME score, age $<5$ & 5218 & 73 & -0.03 & 1.01 & 0.56 & -5 & 2 \\
\hline Birth order & 7126 & 100 & 2.06 & 1.13 & 0.00 & 1 & 10 \\
\hline Number of children in $\mathrm{HH}$ & 7126 & 100 & 2.96 & 1.14 & - & 2 & 9 \\
\hline Did not graduate/GED by age 19 & 2915 & 79 & 0.16 & 0.37 & 0.19 & 0 & 1 \\
\hline
\end{tabular}

$1-\% N=\%$ imputed. The ICC column reports the intraclass correlation coefficients which reflect the proportion of variance between-families. $l n$ denotes that the natural logarithm is taken when creating this variable. The $\% N$ for did not graduate/ged by age 19 is based on the available sample of 3676.

\subsection{Birth weight}

Children's birth weight was provided by the mother and is not taken from birth records. Although this situation is not ideal, it is generally considered to be valid (Boardman et al., 2002; Conley and Bennett, 2000; Cramer, 1995). We adjusted for birth weight in two ways in our analysis, both of which used continuous operationalizations. Birth weight is usually entered as one or two dummy variables indicating whether the child's weight was $1500 \mathrm{~g}<x \leq 2500 \mathrm{~g}$ (LBW) or $x \leq 1500 \mathrm{~g}$ (VLBW) for the smallest babies. This dichotomization greatly reduces variation and hence statistical power and VLBW babies are rare in random samples, making sibling-comparisons difficult. As we discuss below, we chose to use continuous operationalizations of birth weight in order to fully utilize between-sibling variation. Our parameterizations were guided by the use of nonparametric Lowess curves (Cleveland, 1979; Royston, 1991) which capture the relationships between birth weight and our outcomes without making assumptions about the functional form (see Figure 2 and Figure 3 for comparisons with our modelbased parametric estimates). In addition, and with regards to between-sibling birth weight variation, as noted in Table 1, the intraclass correlation (ICC), which measures the proportion of variance between-families (the between-family variance relative to the total variance), indicated that substantial variance in birth weight was within-families $(1-.4=.6 \%$ or $60 \%)$.

The first coding implemented for the cognitive development growth models included birth weight as a quadratic function based on the functional form suggested by the Lowess curves (Figure 2). The linear Birth weight $t^{5}$ term was transformed for the analysis by subtracting $2500 \mathrm{~g}$ and dividing by 1000 so that parameter estimates reference children at the low birth weight (LBW) borderline while expected increments as indicated by the linear birth weight coefficient are in $1000 \mathrm{~g}$ (grams) units. This means that a value of +1 references approximately average birth weight children $(\bar{x} \approx 3300 \mathrm{~g}$; NBW), while a value of -1 references children at the very low birth weight cutoff of $1500 \mathrm{~g}$ (VLBW). Birth weight ${ }^{2}$ was also included to allow the relationships between birth weight, reading development, and high school completion to be non-linear (see Figure 2). This coding was implemented to facilitate birth weight category comparisons corresponding to those using the normative dummy variable approach. Note, also, that the range of family-centered or between-sibling birth weight comparisons (level-2 in our models) was between -1.96 and +1.73 (-1960 to $1730 \mathrm{~g}$ ) indicating that we have adequate within-family birth weight variation to cover the $\pm 1000 \mathrm{~g}$ range of our effect coding (we also validated this by visually inspecting histograms, omitted for parsimony).

The second operationalization used a piecewise approach for the timely high school completion models. As with the quadratic shape for the cognitive development models, the piecewise formulation was chosen to reflect the relationship shown by the nonparametric Lowess curve relating birth weight to the probability of high school completion (see Figure 3). The two pieces of the birth weight effect are for birth weights less than the average birth weight (3300 g) and above the average, divided by 1000 . The above average piece is 0 whenever the below average piece is nonzero, and vice ver-

5. We also explored the impact of prematurity individually and in models adjusting for birth weight. Prematurity, however, had little impact on our parameter estimates and was not associated with our outcomes so we have omitted that variable from the analyses we present here. 
sa. Thus, two coefficients are estimated for the first and second parts of the birth weight distribution. When the values for both pieces are 0 the model expectation is for an average birth weight child, a value of -1 on the first piece then captures the difference for the LBW-NBW comparison, and -2 the VLBW-NBW comparison.

\subsection{Time-invariant covariates}

We included early childhood covariates (child's age $<5$ ) as temporally-invariant predictors of children's reading recognition growth. These predictors capture important elements of family life and child experiences that may vary between siblings and that are also known to vary considerably across families with implications for youth development. For the multilevel growth models these variables are centered at the family means for the level-2 within-family, between-siblings covariates, and then the family means are included in the level-3 between-family part of the model (grand-mean centered). Covariates included whether or not the child is Female (=1; level-2 and -3 ), and whether or not the primary racial designation is Black or Hispanic (=1; level-3).

Between-families we also incorporated a standardized measure of the Maternal Armed Forces Qualifying Test (AFQT) as a measure of maternal cognitive achievement $(\bar{x}=0, \sigma=1$; level-3) in addition to a standardized measure of the full Early HOME Score ( $\bar{x}=0, \sigma=1$; level-2 and -3) from the Home Observation for Measurement of the Family Environment (Bradley and Caldwell, 1984a, 1984b). The HOME score is a commonly used measure of the cognitive and supportiveness of the environment for children's development (e.g., Farkas and Beron, 2004). We chose to use the entire HOME scale, which is composed of physical environment, cognitive stimulation, and parenting style subscales, in order to simplify the model by reducing the number of covariates entered into the equations. Additional covariates included Early Poverty, coded as whether or not the youth experienced a poverty spell prior to age $5(=1$; level-2 and -3), Early ln(income), the natural logarithm of the average early family childhood income (level-2 and -3), and whether the child was born to a never married single mother (=1; Early Single Parent), or a divorced mother/parent (=1; Early Divorce, level-2 and -3), and Birth Order (level-2 and -3) since there may be resource dilution effects in larger families.

\subsection{Time-varying covariates}

Family circumstances vary over time and so will vary across siblings given the variation in that timing. Each of these covariates was included in the level- 1 within-person part of the model and was centered at the age-specific family means, in addition to the wave-specific family means in the time-varying portion in the level-3 between-families part of the mod$\mathrm{el}^{6}$ (level-3 variables are centered at their grand means). The age-specific time-varying covariates include a standardized HOME Score $(\bar{x}=0, \sigma=1)$, whether the youth experience a Poverty $(=1)$ spell between assessments, the natural logarithm of income, $\ln$ (Income) at the current age of assessment, and whether the child lived with a never married Single (=1) parent, or whether the youth lived with a Divorced $(=1)$ mother or parent/guardian.

\subsection{Analytic approach}

Our analytic approach was based around the model shown in Figure 1. This model depicts (a) a growth model with freely estimated factor loadings and (b) a mediation model with paths from birth weight to growth rates and paths from these growth rates and birth weight to high school completion. The free-loading factor model (Bollen and Curran, 2006) allowed us to estimate a non-linear curve with only two growth parameters - normal approaches would require an intercept, linear time term, and quadratic term with this data and outcome to capture growth as a decelerating function of age. The approach we adopted fits a term for the intercept, capturing cognitive development at age 5 , and the temporal slope capturing total growth by age 14 . Nonlinearities in the growth rates were reflected in the factor loadings $\left(\lambda_{t}=0, \lambda_{1}, \lambda_{2}, \lambda_{3}\right.$, 1). The first factor loading was set to 0 to fix the intercept and the last loading was fixed to 1 to set the temporal slope to be total growth. This means that $\lambda_{1}, \lambda_{2}, \lambda_{3}$ each captured the proportion of growth achieved by that age $(8,10,12)$. Thus, the birth weight (and other) coefficients captured expected differences in cognitive development by age 5 and, for the slope, differences in total growth by age 14. In addition, although not noted in Figure 1 for simplicity, the time-changing covariates would be captured by displaying boxes above the wave-specific development measures with paths interlinking them. These effects were held constant over time in our models and the paths were contemporaneous (rather than lagged) to reflect the fact that our ages actually capture age groups.

In the traditional univariate multilevel approach (Raudenbush and Bryk, 2002) the top part of Figure 1 containing the age-specific development (and additional) measures is the level-1 or within-person part of the model. The growth parameters and birth weight (and other) fixed covariates are level-2 - the within-family, between-sibling part of the model. Not depicted in Figure 1 is the generalization to level-3, the between-family part of the model which captures variation across families. This part of the model is essentially identical to the level- 1 and 2 depiction in Figure 1 but where each parameter/covariate is replaced with the family average. In this context the level-2 growth parameters reflect variation between siblings such as differences in growth from the family average, and the level-3 parameters reflect variation between-fami-

6. There is some mixing and matching of model referencing here because time-variation can easily appear on the within-family and betweenfamily parts of the model in the structural equation estimator used. All time changing variables would appear in level-1 for the classic univariate multi-level approach (e.g., Raudenbush and Bryk, 2002). 


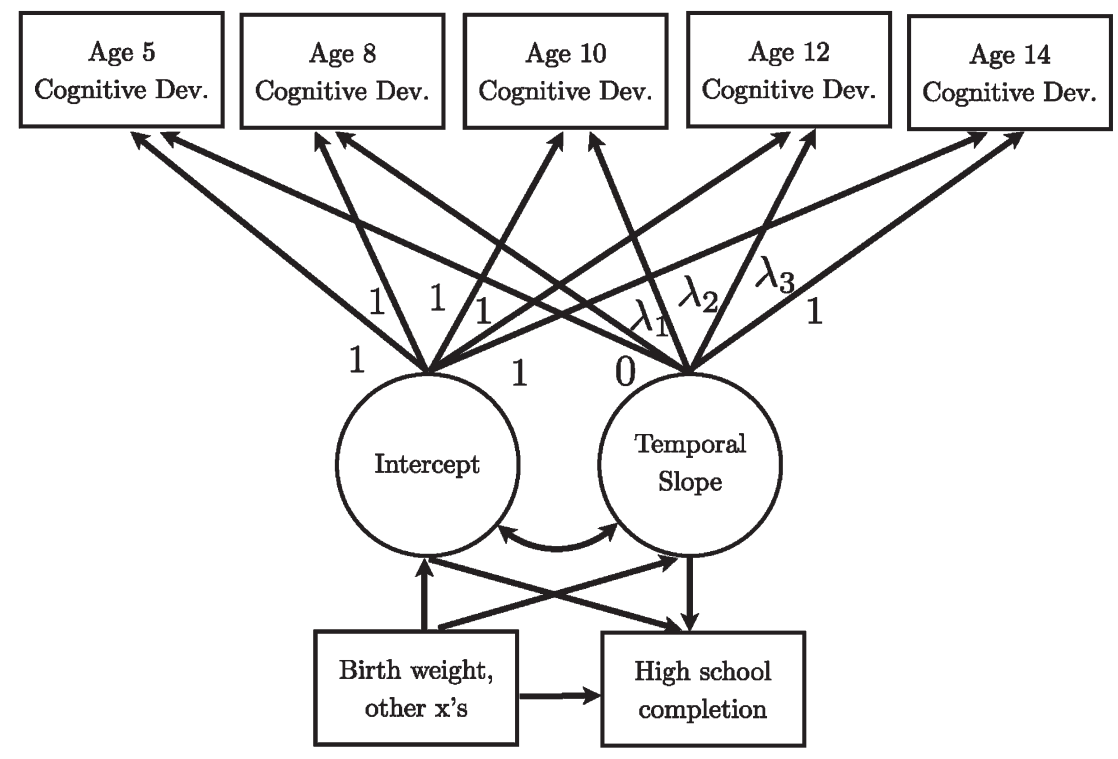

Figure 1. Simplified graphical depiction of the free-loading latent growth curve and path model.

lies such as differences in average family growth from average growth for the sample. For a more mathematical treatment of a similar model see Goosby and Cheadle (2009).

The model is generalized to a full path model for the educational attainment analysis by including the dichotomous high school completion indicator in which all parameters, including the cognitive development growth factors, are estimated simultaneously. In the full multilevel model this becomes a random intercept probit equation so the coefficients are $z$-scores. ${ }^{7}$ We discuss these models in the text as two-level models because the growth parameters (level- 2 above) are treated as covariates for the high school completion outcome. In other words, there are no repeated high school completion measures and so we consider level-1 to be between siblings (within-family) and level-2 to be between-families. The random intercept thus reflects family-level heterogeneity in the likelihood of not completing high school or having obtained a GED by or after age 19.

Conceptually, our multilevel approach was based upon the decomposition for multilevel covariance structure analysis of Muthén $(1994,1997)$, where the total covariance matrix, $\Sigma_{T}$, is decomposed into within- and between-covariance matrices, $\Sigma_{W}+\Sigma_{B}$ comprising level-1 and 2 (within-family) and level-3 (between-family). The important aspect of this decomposition was the orthogonal construction of the estimator for $\Sigma_{W}$ which uses group-mean centering to construct the within-family covariance matrix. In contrast, the total covariance matrix $\left(\Sigma_{T}\right)$ used in traditional single-level analysis grand mean centers the sample (e.g., Bollen, 1989) and so does not account for omitted factors. When group-means are related systematically to the developmental process along with the focal exogenous variables, and they are not accounted for, regression parameters will be biased by their omission. This is why econometric fixed effects (i.e., dummy variables for each family) which capture these correlations and random-intercept estimators often produce different parameter estimates (see Allison, 2005; Raudenbush and Bryk, 2002). That is, this approach controls for factors which similarly influence siblings which we do not have controls for. Accounting for these correlations is one of the strengths of the sibling model with fixed effects or group-mean centered random effects models and the reason why these approaches are often preferable to normal regression or random effect models without group-mean centering.

\section{Results}

\subsection{Descriptive statistics}

Descriptive statistics for the sample are presented in Table 1 ( $N$, mean, standard deviation [SD], min, max), along with the \% missing (implying the \% imputed) and the intraclass correlation (ICC). The ICC is presented to provide information on the amount of variation in each variable that resides between-families. High ICCs indicate that most of the variation in a measure (e.g., family structure) is between, rather than within, families. Variables that only vary between-families are unable to explain differences between siblings. Average cognitive development increased from 17 points to 60 points over the study period and the ICC increased over time, although there was substantial variation between-families across waves. Approx-

7. Maximum likelihood estimation of multilevel path models with non-normal/continuous outcomes become very computationally intensive/ expensive very quickly (and much more again when one model must be estimated for each imputed data set). In order to jointly estimate all parameters, we made use of the multilevel weighted least squares estimator detailed in Asparouhov and Muthén (2007) which estimates probit rather than logit equations for dichotomous outcomes. 
imately $16 \%$ of youth age 19 and above failed to graduate or receive a GED by or after age 19, and the ICC (.19) indicated that substantial variation was within-families. The average birth weight was approximately $3300 \mathrm{~g}$ with a standard deviation (SD) of $600 \mathrm{~g}$. Notably, there was substantial variation in birth weight both within- and between-families (ICC $=.4$ ). The sample was $32 \%$ black and $21 \%$ Hispanic and thus had a slightly higher proportion of minority youth than the NLSY in general (28\% and $19 \%$, respectively), reflecting larger average family sizes among black and Hispanic respondents. The average number of siblings per household was 3 and the average maternal age at the youth's birth was 24 years. ${ }^{8}$

\subsection{PIAT cognitive development growth}

Coefficient estimates partially standardized with respect to the growth parameters ${ }^{9}$ and absolute $z$-ratios (coefficient $\div$ standard error) for the cognitive development free-loading growth models are presented in Table 2. Partially standardized coefficients are interpreted as a 1-unit change in $x$ predicting a $\beta$ standard deviation change in $y$ (age 5 and subsequent growth, here). Model M1 reports the growth model with birth weight, M2 adds the family variables, M3 generalizes M1 to the three-level framework, while M4 generalizes M2. Across models (M1-M4) the Standardized Root Mean Square Residual (SRMR), a measure of model fit (<.1 indicating good fit; Kline, 1998), is included in the tables. This statistic was chosen because it can be decomposed to summarize the fit between the expected and observed covariance structures for both the within (level-1 and -2) and between (level-3) parts of the model. The birth weight gradients for the intercept and temporal slope are depicted graphically in Figure 2. The curves for M3 and M4 reflect the level-2 betweensibling effect estimates. In M1 the factor loadings were .37, .65, and .85, indicating that $37 \%$ of growth had occurred by age $8,65 \%$ by age 10 , and $85 \%$ by 12 years. These results were consistent across specifications.

The birth weight gradient in M1 indicated that averaged sized youth (NBW; $3500 \mathrm{~g}$ ) at age 5 had scores $(.27-.06)^{10}$ .21 standard deviations (SD) higher than those born at the LBW $(2500 \mathrm{~g})$ cutoff. The LBW-VLBW gap was estimated to be $(-1] .27-.06)^{11}-.33 \mathrm{SD}$, a sizeable gap, and the NBW-VLBW averaged $(.21+.33) .54$ SD. Figure $2 \mathrm{~A}$ shows that this gap was slightly larger than the nonparametric Lowess estimates and that, moreover, the bend at larger estimates was underestimated by the quadratic formulation. ${ }^{12}$ Results were consistent, however, over the majority of the birth weight distribution. Somewhat surprisingly, the largest reduction in the birth weight effect magnitude across specifications was in M2 $(\mathrm{NBW}-\mathrm{LBW}=.1 \mathrm{SD} ; \mathrm{LBW}-\mathrm{VLBW}=.22)$ although the differences remained significant across specifications as indicated by the $z$-ratios larger than 1.96. By M4 the estimated gaps were (NBW-LBW) .18SD and (LBW-VLBW) .24 SD. These results are consistent with the interpretation that although part of the birth weight gap in cognitive development in childhood result from adverse social circumstances, a substantial portion of the effect estimates result from biological insult.

The results for cognitive development growth from ages 5 to 14 suggested that social background plays a larger biasing role in birth weight gradients during this than the earlier period. As shown in panel B of Figure 2, the M1 results closely tracked the nonparametric relationship between birth weight and growth over most of the birth weight distribution. The estimated gaps in M1 were (NBW-LBW) .18 SD and (LBW-VLBW) .33 SD and were reduced to (NBW-LBW) .07 SD and (LBW-VLBW) .15 SD by model M4 (coefficient estimates were consistent for M2-M4) where the linear term was only marginally statistically significant $(z=1.94)$ and the quadratic term was not significant $(z=1.3)$. The reduction in coefficient bias in models M2-M4 is discernable graphically and is consistent with the interpretation that naive birth weight estimates will be biased upward by social background factors if not accounted for.

The level-3 between-family birth weight associations are more difficult to interpret - many temporally-invariant factors are accounted for in the level-2 model with the inclusion of the level-3 random effects and group-mean centering (Allison, 2005). For the level-3 model it is possible that a great many omitted factors continue to bias the relationship between average family birth weight and average family cognitive growth. The results indicated, however, that birth weight was strongly associated with growth (M3) and that a substantial proportion of the effect-size estimate is due to family circumstances, which is consistent with M2. In fact, the linear relationship with the temporal slope was only marginally significant $(z=1.91)$ and the quadratic term was non-significant $(z=1.61)$ in model M4, which includes between-family characteristics. These results are consistent with the interpretations that much of the association between family-average birth weight and family-average cognitive development is due to background factors associated with birth weight.

Additional results indicated that model fit improved across specifications as shown by the SRMR decreasing from .12 (M1) to nearly 0 (M4). In addition, nearly $25 \%$ and $20 \%$ of the variance in the intercept and temporal slope (M2), respectively, was explained with the background variables. The results for M4, however, indicated that most of the explained variation reflected variation between- rather than within-families. For the additional covariates the most stable results indicated that the early home environment was an important predictor of early development between siblings (level-2), and that youth from families with higher early HOME scores (level-3) had higher childhood scores and growth rates than children in families with lower scores. Girls (level-2) and families with more girls (level-3) also outperformed the boys

8. There was one reported age of 11,5 of 13 years, and 26 at 14 years. Results were invariant to our treatment of these values.

9. Those standardized continuous covariates such as the early home score are thus fully standardized. Dichotomous variables reflect standardized differences.

10. Calculated as $\beta_{1} x+\beta_{2} x^{2}=\beta_{1} 1+\beta_{2} 1^{2}=.27 \times 1-.06 \times 1=.21$.

11. Calculated as $\beta_{1} x+\beta_{2} x^{2}=\beta_{1}(-1)+\beta_{2}(-1)^{2}=.27 \times(-1)-.06 \times 1=.33$.

12. There were 745 cases with birth weights above $4000 \mathrm{~g}$ and 127 above $4500 \mathrm{~g}$. 
Table 2. Single-level and multilevel growth models of cognitive development $(N=7126$, multiple imputation data sets $=10)$.

\begin{tabular}{|c|c|c|c|c|c|c|c|c|}
\hline \multirow[b]{3}{*}{ Variable/parameter } & \multicolumn{4}{|c|}{ Two-level } & \multicolumn{4}{|c|}{ Three-level } \\
\hline & \multicolumn{2}{|l|}{ M1 } & \multicolumn{2}{|l|}{ M2 } & \multicolumn{2}{|l|}{ M3 } & \multicolumn{2}{|l|}{ M4 } \\
\hline & $b$ & $z$ & $b$ & $z$ & $b$ & $z$ & $b$ & $z$ \\
\hline $\begin{array}{l}\text { Intercept, level-2 (within-family) } \\
\text { Birth weight } \\
\text { Birth weight }{ }^{2} \\
\text { Female } \\
\text { HOME score, age }<5 \\
\text { Income }(\ln ), \text { age }<5 \\
\text { Single mother, age }<5 \\
\text { Divorced mother, age }<5 \\
\text { Mother's age at birth } \\
\text { Birth order }\end{array}$ & $\begin{array}{r}0.27 \\
-0.06\end{array}$ & $\begin{array}{l}(7.57) \\
(2.76)\end{array}$ & $\begin{array}{r}0.16 \\
-0.06 \\
0.17 \\
0.15 \\
0.05 \\
0.01 \\
0.08 \\
0.03 \\
-0.09\end{array}$ & $\begin{array}{l}(5.14) \\
(3.16) \\
(7.82) \\
(9.70) \\
(2.41) \\
(0.30) \\
(1.96) \\
(8.51) \\
(7.54)\end{array}$ & $\begin{array}{r}0.21 \\
-0.04\end{array}$ & $\begin{array}{l}(4.06) \\
(1.37)\end{array}$ & $\begin{array}{r}0.21 \\
-0.03 \\
0.20 \\
0.15 \\
-0.03 \\
0.02 \\
0.11 \\
0.02 \\
-0.03\end{array}$ & $\begin{array}{l}(3.97) \\
(0.81) \\
(6.38) \\
(4.66) \\
(1.34) \\
(0.31) \\
(1.47) \\
(2.30) \\
(0.99)\end{array}$ \\
\hline $\begin{array}{l}\text { Time-varying, level-3 (between-family) } \\
\text { HOME score } \\
\text { Single mother } \\
\text { Divorced mother } \\
\text { Income }(\ln )\end{array}$ & & & & & & & $\begin{array}{r}0.03 \\
0.02 \\
0.02 \\
-0.01\end{array}$ & $\begin{array}{r}(3.75) \\
(0.34) \\
(0.69) \\
(-0.62)\end{array}$ \\
\hline $\begin{array}{l}\text { Slope level-3 (between-family) } \\
\text { Birth weight } \\
\text { Birth weight }{ }^{2} \\
\text { Female } \\
\text { Black } \\
\text { Hispanic } \\
\text { Mother's AFQT } \\
\text { HOME score, age }<5 \\
\text { Income }(l n) \text {, age }<5 \\
\text { Single mother, age }<5 \\
\text { Divorced mother, age }<5 \\
\text { Mother's age at birth } \\
\text { Birth order }\end{array}$ & & & $\begin{array}{r}-0.18 \\
0.08 \\
0.28\end{array}$ & $\begin{array}{r}(4.28) \\
(2.06) \\
(15.24)\end{array}$ & $\begin{array}{r}0.51 \\
-0.10\end{array}$ & $\begin{array}{l}(5.05) \\
(1.66)\end{array}$ & $\begin{array}{r}0.18 \\
-0.09 \\
0.13 \\
-0.25 \\
0.15 \\
0.46 \\
0.21 \\
0.00 \\
-0.25 \\
-0.03 \\
-0.01 \\
-0.18\end{array}$ & $\begin{array}{r}(1.91) \\
(1.61) \\
(1.83) \\
(3.59) \\
(2.32) \\
(15.29) \\
(6.19) \\
(0.04) \\
(2.70) \\
(0.22) \\
(1.35) \\
(4.59)\end{array}$ \\
\hline $\begin{array}{l}\text { Variance explained, } R^{2} \\
\text { Level-2 intercept } \\
\text { Level-2 slope } \\
\text { Level-3 intercept } \\
\text { Level-3 slope }\end{array}$ & $\begin{array}{l}0.02 \\
0.01\end{array}$ & $\begin{array}{l}(4.39) \\
(3.59)\end{array}$ & $\begin{array}{l}0.24 \\
0.19\end{array}$ & $\begin{array}{l}(21.29) \\
(18.41)\end{array}$ & $\begin{array}{l}0.00 \\
0.00 \\
0.03 \\
0.04\end{array}$ & $\begin{array}{l}(0.00) \\
(0.00) \\
(3.14) \\
(3.56)\end{array}$ & $\begin{array}{l}0.02 \\
0.01 \\
0.49 \\
0.48\end{array}$ & $\begin{array}{r}(5.11) \\
(3.91) \\
(21.04) \\
(19.14)\end{array}$ \\
\hline
\end{tabular}


Table 2. Continued.

\begin{tabular}{|c|c|c|c|c|c|c|c|c|}
\hline \multirow[b]{2}{*}{ Variable/parameter } & \multicolumn{4}{|c|}{ Two-level } & \multicolumn{4}{|c|}{ Three-level } \\
\hline & $b$ & $z$ & $b$ & $z$ & $b$ & $z$ & $b$ & $z$ \\
\hline \multicolumn{9}{|l|}{ Model fit } \\
\hline$x^{2}(\mathrm{df})$ & \multirow{3}{*}{\multicolumn{2}{|c|}{$\begin{array}{l}10,362(37) \\
0.12\end{array}$}} & \multirow{3}{*}{\multicolumn{2}{|c|}{$\begin{array}{l}11,734(164) \\
0.04\end{array}$}} & \multicolumn{2}{|c|}{$10,746(54)$} & \multicolumn{2}{|c|}{$12,615(297)$} \\
\hline SRMR, within & & & & & \multicolumn{2}{|c|}{0.09} & \multicolumn{2}{|c|}{0.02} \\
\hline SRMR, between & & & & & \multicolumn{2}{|l|}{0.00} & \multicolumn{2}{|l|}{0.02} \\
\hline
\end{tabular}

a Standardized with respect to the wave-specific achievement scores.

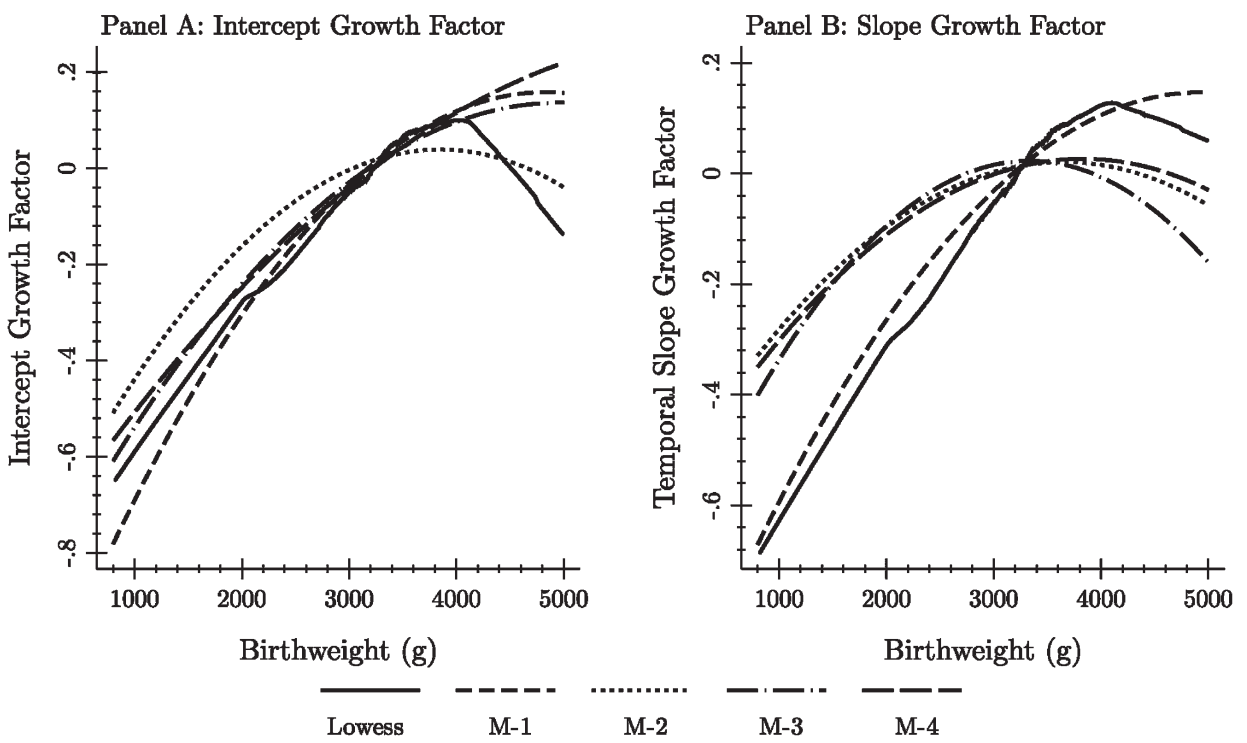

Figure 2. Birth weight effect estimates for standardized growth factors (Table 2).

in childhood. Maternal AFQT was the strongest predictor in the model, indicating that youth with high scoring mothers themselves had higher average scores (as a family). In addition, younger siblings/youth from larger families had smaller growth parameters (both level-2 and 3). The black coefficient for the intercept was positive in M2 and M4. This finding arises when maternal AFQT is entered into the equation and arises because of the substantial black-white differences in the maternal AFQT distribution. Notably the black-white advantage at age 5 decreased with time in these models while Hispanic youth, who scored no differently than whites' at age 5, had slightly faster growth rates. It is also important to recognize that these parameters refer to family averages and not specifically to individual outcomes.

Finally, results for the time-changing covariates are also reported in Table 2. Although the home scores and income were related to sibling variation (level-2) in M2 and M4, the effect-sizes were small, indicating that variation between siblings produced only a small amount of variance in age-specific outcomes between siblings. This part of the model is "net of" the growth parameters which themselves explain a great deal of variation in the age-specific development scores $\left(R^{2}>\right.$ .91 ) and so absorb most of the explainable variance in these outcomes.

\subsection{High school completion}

One of Conley and Bennett's (2000) major findings using the PSID was that birth weight is a very strong predictor of between-sibling variation in high school completion. We elaborate Conley and Bennett's work in Table 3, again making use of continuous birth weight measures. In this case, piecewise functions of birth weight - one slope for birth weight below the average $(3300 \mathrm{~g})$, and another for birth weight above the average. The shape of this function was motivated by the nonparametric Lowess curve shown in Figure 3. Model N1 included only birth weight and N2 included the growth parameters (intercept and slope) for the single-level model. Model N3 generalizes N1 to the multilevel context, while N4 generalizes N2. The coefficients are in the probit metric. Here level-1 refers to the within-family, between-siblings model and level-2 refers to the between-family part of the model. No fit statistics are supplied because we are dealing with a single outcome and any fit statistics for models N2 and N4 would reflect primarily the fit of the growth model.

The significant linear trend for below average birth weight (N1; $z=3.55$, Table 3) closely matched the nonparametric Lowess curve in Figure 3. The probability of not completing high school decreased steadily with birth weight until approxi- 
Table 3. Single-level and multilevel logistic regression models predicting not completing high school or obtaining a GED by age, $19(N=5280$, multiple imputation data sets $=10)$.

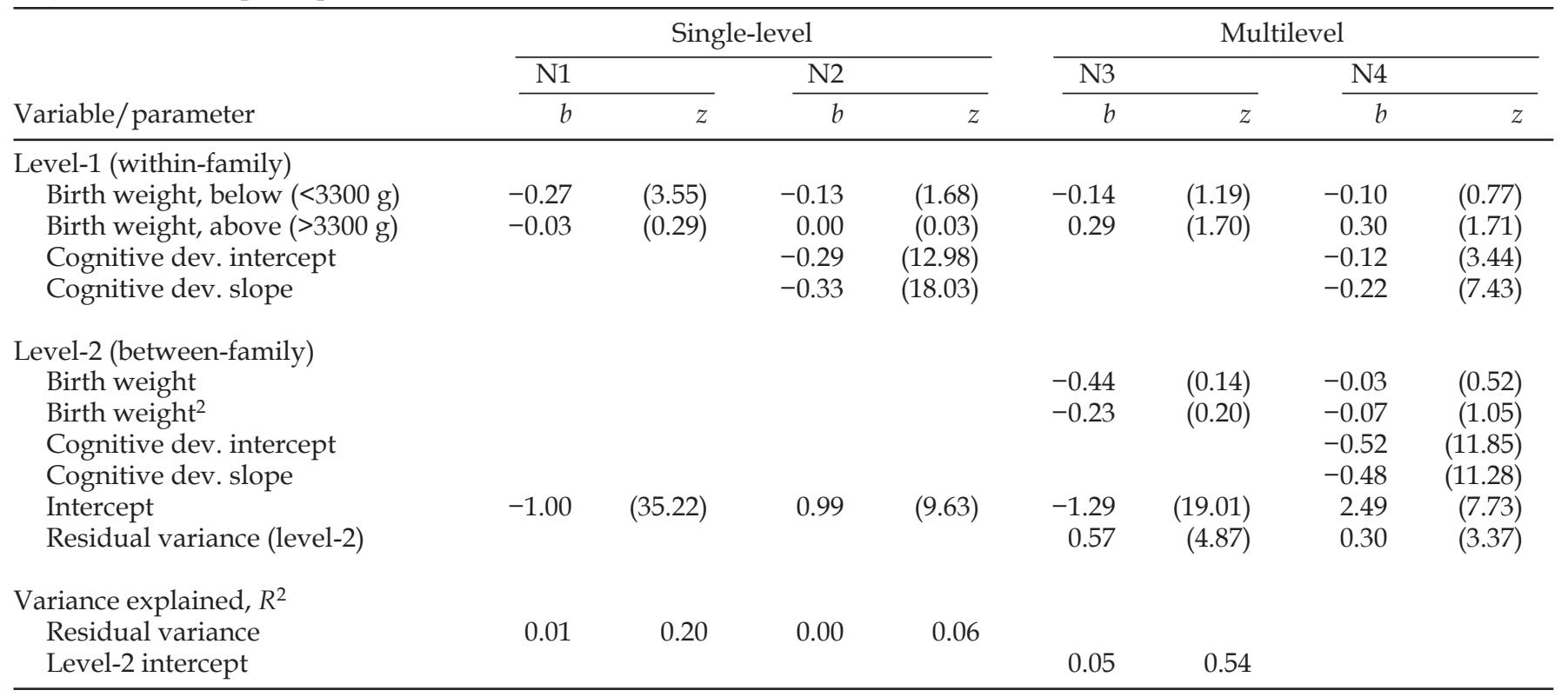

Absolute z-ratio values are shown in parentheses.

The coefficients for the growth parameters have been standardized to have a variance of 1 . The means, however, have not been fixed to 0 and are available upon request.

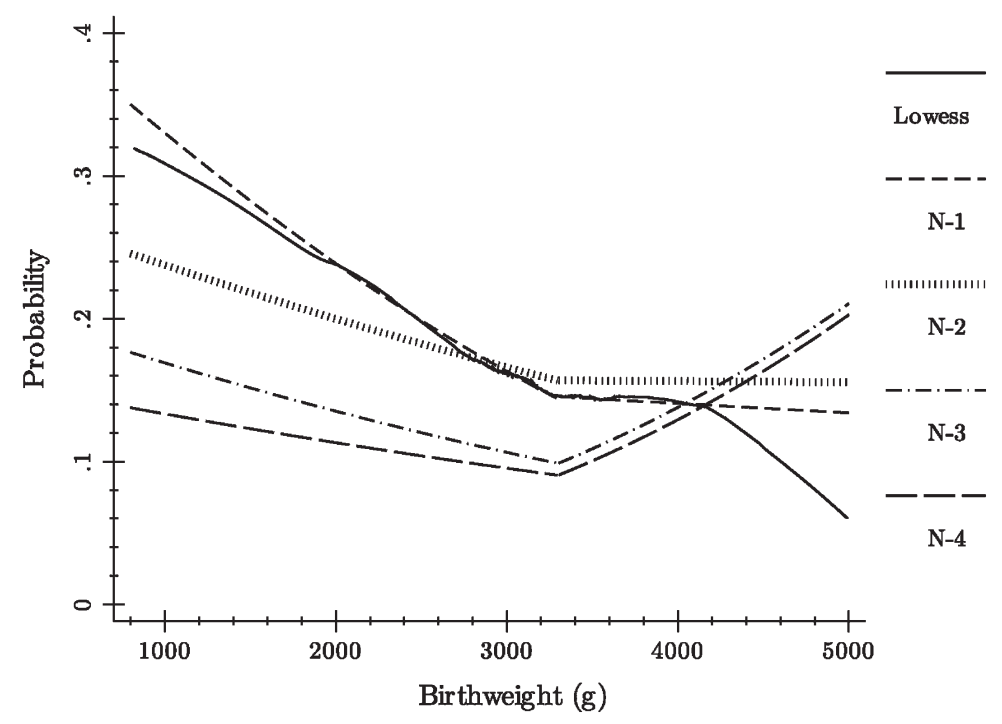

Figure 3. The probability of not graduating from high school by birth weight (Table 3).

mately $3300 \mathrm{~g}$, after which the relationship was statistically zero. The Lowess curve trails downward again at the larger birth weights, but it is important to recognize that there are few births of these sizes and so the estimate may be somewhat unstable, although this finding may also be indicative of a macrosomic effect (Cesur and Rashad, 2008). The linear term was reduced to nonsignificance $(z=1.68)$ in N2 when the growth parameters were included, indicating that the association between birth weight and high school completion results from slower cognitive development. Model N3 indicated that the estimated below average birth weight gradient in N1 is the result of between-family differences in risk which is accounted for by the family-centering strategy so that siblings of different birth weights do not differ statistically from each other, on average, once fixed-family characteristics are accounted for. Although the between-family (level-2) birth weight effect in N3 was not significant, the coefficients were reduced virtually to zero when cognitive trajectories were included in N4. Thus, these simple models suggest that birth weight is associated with high school completion through past cognitive development. To our knowledge, this is the first paper that has demonstrated that the relationship between birth weight and attainment operates directly through achievement processes resulting from early childhood disparities. 
Although we do not report results for models including our full covariate list in Table 3, we estimated those models as well (results available upon request). We have omitted these results from Table 3 because the results for the focal parameters were similar to those reported in N4. ${ }^{13}$ Briefly, those results indicated that none of our early childhood predictors was related to differences between siblings (level-1) once cognitive growth was accounted for. Black youth (level-2) were more likely to graduate on time, while those from larger and single parent families were less likely to finish high school, all else equal.

\subsection{Birth weight and family background moderation}

We tested for interactions between birth weight and the family covariates for both cognitive development growth (intercept and slope) and timely high school completion in (a) single-level models, (b) within-family (level-2 for the growth models and level-1 for high school completion), and (c) between-families (level-3 for the growth models and level-2 for high school completion) in the multilevel models. We assessed the interactions three ways. ${ }^{14}$ First, we tested whether or not the sum of the absolute value of the interaction coefficient values were zero (this can be viewed as a $z$-test or $\chi^{2}$ with $1 \mathrm{df})$. Second, we conducted joint $F$-tests that the parameters were zero using factor scores of the growth parameters as dependent variables in random intercept models using the multiple imputation analysis procedures in Stata 11. Third, we used likelihood-ratio $\chi^{2}$ tests to compare models with the interactions to those without for a subset of the interactions (Schafer, 1997).${ }^{15}$ The models were estimated with only the main effects for the covariate and birth weight along with the interaction terms, making the tests somewhat liberal. For the high school completion models we also assessed whether birth weight and cognitive development growth interacted.

The results, which have been omitted to save space and are available upon request, indicate that the developmental consequences of birth weight for cognitive development appear to be consistent across a range of family characteristics. The set of null findings holds for single-level population-based models, and within- and between-families. Thus, the developmental birth weight impacts reported in Table 2 appear to influence all youth similarly. Conley and Bennett (2001) suggested that income may act as a developmental buffer for the relationship between birth weight and high school completion, although their results suffer from a lack of statistical power and do not persist for their most persuasive fixed-effects model. Once again, we found little evidence of birth weight moderation, particularly in the conceptually stronger multilevel models.

\section{Discussion}

Our principal goal in this paper was to elaborate the complex interplay between health at birth and educational development from childhood into early adulthood. This study contributes to research on the relationship between health and status attainment which we have viewed as part of the larger puzzle of how health and achievement processes are interlinked over the life course (Hayward et al., 2000; Hayward and Gorman, 2004). We compared the cognitive growth of siblings with different birth weights and then used these trajectories as mediators of the relationship between birth weight and high school completion. This approach allowed us to model a long-term developmental and attainment sequence beginning in the womb and culminating in timely high school completion. Our study addressed the following central questions: (1) Is birth weight related to cognitive development in childhood and (2) are there birth weight differences in cognitive growth into adolescence? (3) Is birth weight associated with timely high school completion and (4) is the relationship accounted for by cognitive development? Finally, (5) do birth weight associations persist when controlling for confounding factors that are constant within-families or vary between siblings in the same families?

Like Boardman et al. (2002) and Goosby and Cheadle (2009), the results of the single-level analyses indicated nontrivial birth weight gradients in children's development by age 5. Unlike Boardman et al., who found that reading gaps do not grow and may even converge over time (see also Hillemeier et al., 2009), we found marginal evidence that gaps continue to increase through age 14. Our results could differ because Boardman and colleagues used percentile scores, which are by definition bounded (i.e., ceiling and floor) so that change over time within age groups was concealed by regression to the mean. Though reduced in magnitude after comparing siblings, we found that birth weight gradients with cognitive growth persisted across model specifications, although the relationship was marginal in the most stringent model. Thus, our sibling comparisons with explicit attempts to model within-family heterogeneity suggested that lower birth weight children have poorer cognitive skills at age 5 and that, furthermore, these children acquire fewer skills as they develop through age 14 .

How important are these differences? Results from model M4 in Table 2 between youth born 3500-1500 g (NBWVLBW) was estimated at .42 standard deviations. The gap was smaller but still a nontrivial .18 standard deviations for the 3500-2500 g (NBW-LBW) comparison and .24 standard deviations for the 2500-1500 g (LBW-VLBW) contrast. These ef-

13. The within-family coefficient for the intercept growth factor was $-.12[z=-3.6]$ and temporal slope coefficient was $-.2[z=-6.5]$. At the between-family level the coefficients were $-.38[z=-6.1]$ and $-.4[z=-6.6]$, respectively.

14. Because MODEL TEST which is used in Mplus v5.21 to conduct Walt $\chi^{2}$ did not work with our models when conducting multiple imputation analysis, and because each alternative approach had strengths as well as weakness, we used different methods to ensure confidence in the results.

15. We were only able to do this with the growth models, however, using a non-robust maximum likelihood estimator (the results in text use a robust estimator), because we were unsure how to generalize the non-central $\chi^{2}$ comparison test for the weighted least squares estimator used for the high school completion models to the multiple imutation comparison F-test outlined by Schafer (1997, p. 115). 
fects are sizeable and indicate important birth weight gaps in learning between siblings early in life. The gaps in growth were smaller, however, approximately .22, .07, and .15 standard deviations for the NBW-VLBW, NBW-LBW, and LBWVLBW comparisons, respectively. Although only marginally significant, these effects are not overwhelming, but they indicate a pattern of disadvantage that persists across childhood and into adolescence.

Moreover, the consequences of low birth weight extend beyond development with implications for life chances. In accord with Conley and Bennett $(2000,2001)$ and Conley et al. (2003), we also found that sibling birth weight differences are related to the probability of timely high school completion or GED acquisition. We integrated the model of cognitive development into the estimation of timely high school completion, finding that the birth weight gradient in completion was fully mediated by cognitive development. Moreover, the indirect effects of birth weight through early $(z=2.5)$ and subsequent development $(z=3.4)$ were statistically significant (results not shown; multilevel model). How important is this indirect effect? The result can be approximated from the coefficients in Table 2 and Table 3. Using the standardized birth weight results from the previous paragraph, the change in the $z$-score of not graduating on time would be .05 via both the cognitive development intercept and slope (total $\approx .1$ ) for the NBW-VLBW sibling comparison - an increase in the odds of about 17\% (see Long, 1997, p. 49). The total is approximately .04 for NBW-LBW comparison, or an indirect birth weight effect that raises the odds of not completing on time by approximately $8 \%$. Although these indirect effects are modest in magnitude, this pattern of findings paints the clearest picture yet of childhood health disadvantage extending into early adulthood through early cognitive development. Although not shown, additional analyses suggested that cognitive development at age 5 did not fully distinguish siblings - subsequent growth was also needed in order to explain gaps in high school completion. Thus, the implication is that both early achievement and growth are needed in order to account for the birth weight association with finishing school.

The reach of birth weight into both childhood and young adulthood appears to be consistent across circumstances. Others have suggested that the influence of birth weight may be graded by other indicators of family background and experiences (as noted in Hack et al., 1995). For example, Conley and Bennett (2001) reported mixed evidence that birth weight and income interact (see also Conley et al., 2007). We found few (and no robust) indications that the influence of birth weight on both cognitive development and timely high school completion varies according to family income early in children's lives, the early home environment, whether the child is female, family structure, the mothers age at birth, race/ethnic background, maternal AFQT, or cognitive development growth with respect to high school completion. This does not mean that the impact of birth weight cannot be moderated since early intervention programs have been shown to enhance the cognitive development of low birth weight infants (for a short review see Reichman, 2005). The influence of birth weight, however, appears to operate similarly across a range of family environments and this appears to be true both when we compare variation in these characteristics between-siblings and between-families.

The approach we utilized allowed us to look at both sibling and between-family variation in birth weight, family characteristics, and achievement. Large between-family differences in growth were reported, and these between-family differences in growth lead to biases in birth weight estimates when not accounted for, although as we showed, our covariate list accounted for this bias in single-level analyses. Nonetheless, families with small average birth weights have much lower average achievement, although between-family gaps appear to be related to the racial background of the family (i.e., black children are at much greater risks for LBW [Hoyert et al., 2006), differences in the home educational environment, and maternal cognitive scores as measured by the AFQT. Although income was related to average family growth, supplemental analyses suggested family economic circumstances operate indirectly through the home environment, and as the time changing analysis showed, the home environment and income continue to have small influences on cognitive development over time, net of the individual growth process.

The study is limited in a number of ways. Our sample was limited to families with two or more children since our sibling-comparison strategy could not be utilized on single-child homes. To the extent we have identified or at least adequately approximated a causal birth weight effect, our birth weight effects should apply equally to children from single parent family. If resources are used differently in single-child homes, however, our restricted sibling sample may have removed variation important for the estimation of family characteristic by birth weight interactions. There may also be important characteristics that vary between siblings that we were unable to account for with the included variables. If this is the case then our effect estimates may remain biased and cannot be interpreted causally. For example, the HOME inventories we use to control for variations in the home environment may not fully or adequately capture different patterns of parental investment related to birth weight. In addition, we have interpreted family background as leading to spuriousness in birth weight effects rather than as sources of mediation. Parents may disinvest in smaller children, or patterns of investment may be mixtures in the population, with subsamples of parents increasing investments in smaller children with the hope that they can make up for or ameliorate developmental disadvantage, and others marshalling their limited resources for children they believe have better shots at success. These processes could be mediational, on the one hand, but they could also mask birth weight moderation effect estimates, on the other. Parent investments will also be endogenous to the extent children themselves impede or encourage investment (e.g., Chin and Phillips, 2004). Finally, because the smallest children who are at risk both for health and academic complications are quite rare in the population, they are not well-represented in this particular survey. We were able to account for a broad range of birth weights in the US white, black, and Hispanic populations, however, covering the range of all but smallest births, and certainly covering most of the mass of the birth weight distribution. Given this broad coverage and the fact that the very smallest children were not well-represented, these results may be more striking for this fact. 


\section{Conclusion}

Small babies began surviving in greater numbers in the 1960s with the development of a regional neonatal care system and the use of ventilators (Horbar and Lucey, 1995). Another treatment revolution occurred in the 1980s with the development of surfactant and other steroidal treatments that help infant lungs to mature more quickly so that small babies can breathe on their own. These treatments have improved the US infant mortality curve even though there has been no improvement in the birth weight profile for many years. Recent research has suggested that welfare reform resulted in an increase in small births (Kaestner and Lee, 2003), which means that birth weight will most likely continue to be an important childhood risk factor for nontrivial numbers of America's youth. Moreover, obesity increases risk for both low and very high birth weight children (Kiel et al., 2007) and increases in obesity rates in the US are well and often noted.

Conley et al. (2003) showed that birth weight appears to be transferred intergenerationally, indicating that the transmission of health status has important consequences for social attainment and that there is important bidirectionality in the relationship between health and attainment over the life course. Taken with ours, these results paint a picture of the intergenerational transfer of disadvantage via health. The lower birth weight children in our study had parents with fewer economic resources, who created less engaging home environments, were likely to have been lower birth weight themselves, and also had lower average cognitive scores. Their children entered kindergarten with poorer academic skills and, as a consequence, fell behind and were less likely to have finished high school on time. This pattern of disadvantage, which begins in one generation and is passed-on in the womb and the early-life family environment, appears to have long term consequences for the attainments, and thus health over the life course, for the next.

\section{References}

Allison, 2005 • P. D. Allison, Fixed Effects Regression Methods for Longitudinal Data Using SAS, SAS Press, Cary, NC (2005).

Asparouhov and Muthén, 2007 • Asparouhov, T., Muthén, B. O., 2007. Computationally efficient estimation of multilevel high-dimensional latent variable models. In: Proceedings of the 2007 JSM meeting in Salt Lake City, Utah, Section on Statistics in Epidemiology. Available from http:// www.statmodel.com/download/p2t1.pdf

Barker, 1995 • D. J. P. Barker, Fetal origins of coronary heart disease. British Journal of Medicine, 311 (1995), pp. 171-174.

Barker et al., 1993 - D. J. P. Barker, C. Osmond, S. J. Simmonds and G. A. Wield, The relation of small head circumference and thinness at birth to death from cardiovascular disease in adult life. British Journal of Medicine, 306 (1993), pp. 422-426.

Behrman and Rosenzweig, 2004 - J. R. Behrman and M. R. Rosenzweig, Returns to birth weight. Review of Economics and Statistics, 86 (2004), pp. 586-601.

Boardman et al., 2002 - J. D. Boardman, D. A. Powers, Y. C. Padilla and R. A. Hummer, Birth weight, social factors, and developmental outcomes among children in the United States. Demography, 393 (2002), pp. 353-368.

Bollen, 1989 • K. A. Bollen, Structural Equations with Latent Variables, Wiley, New York (1989).

Bollen and Curran, 2006 - K. A. Bollen and P. J. Curran, Latent Curve Models: A Structural Equation Perspective, Wiley-Interscience, Hoboken, NJ (2006).

Bradley and Caldwell, 1984a • R. H. Bradley and B. M. Caldwell, The HOME inventory and family demographics. Developmental Psychology, 20 (1984), pp. 315-320.

Bradley and Caldwell, 1984b • R. H. Bradley and B. M. Caldwell, The relation of infants' home environments to achievement test performance in first grade: a follow-up study. Child Development, 55 (1984), pp. 803-809.

Breslau, 1995 • N. Breslau, Psychiatric sequelae of low birth weight. Epidemiologic Reviews, 17 (1995), pp. 96-106.

Cesur and Rashad, 2008 - Cesur, R., Rashad, I., 2008. High birth weight and cognitive outcomes. NBER Paper \#14524. Available from http:// www.nber.org/papers/w14524

Cheadle, 2008 - J. E. Cheadle, Educational investment, family context, and children's math and reading growth from kindergarten through the third grade. Sociology of Education, 811 (2008), pp. 1-31.

Cheadle, 2009 • J. E. Cheadle, Parent educational investment and children's general knowledge development. Social Science Research, 382 (2009), pp. 477-491.

Chin and Phillips, 2004 - T. Chin and M. Phillips, Social reproduction and child-rearing practices: social class, children's agency, and the summer activity gap. Sociology of Education, 77 (2004), pp. 185-210.

Cleveland, 1979 - W. S. Cleveland, Robust locally weighted regression and smoothing scatterplots. Journal of the American Statistical Association, 74 (1979), pp. 829-836.

Conley and Bennett, 2000 - D. Conley and N. G. Bennett, Is biology destiny? Birth weight and live chances. American Sociological Review, 65 (2000), pp. 458-467.

Conley and Bennett, 2001 - D. Conley and N. G. Bennett, Birth weight and income: interactions across generations. Journal of Health and Social Behavior, 42 (2001), pp. 450-465.

Conley et al., 2007 - D. Conley, K. M. Pfeiffer and M. Velez, Explaining sibling differences in achievement and behavioral outcomes: the importance of within- and between-family factors. Social Science Research, 36 (2007), pp. 1087-1104.

Conley et al., 2003 - D. Conley, K. W. Strully and N. G. Bennett, The Starting Gate: Birth Weight and Life Chances, University of California Press, Berkeley (2003).

Cramer, 1995 - J. C. Cramer, Racial and ethnic differences in birthweight: the role of income and financial assistance. Demography, 322 (1995), pp. 231-247.

Currie and Hyson, 1999 - J. Currie and R. Hyson, Is the impact of health shocks cushioned by socioeconomic status? The case of low birth weight. American Economic Review, 89 (1999), pp. 245-250.

Danzinger et al., 2002 • S. Danzinger, M. Corcoran, S. Danzinger, et al.,Barriers to employment of welfare recipients. PSC Research Report: Population Studies Center, University of Michigan (2002).

Duncan and Brooks-Gunn, 1997 - G. J. Duncan and J. Brooks-Gunn, The Consequences of Growing Up Poor, vol. 1, Russell Sage, New York, NY (1997). 
Farkas and Beron, 2004 • G. Farkas and K. J. Beron, The detailed age trajectory of oral vocabulary knowledge: differences by class and race. Social Science Research, 33 (2004), pp. 464-497.

Godfrey and Barker, 2001 - K. M. Godfrey and D. J. P. Barker, Fetal programming and adult health. Public Health Nutrition, 4 (2001), pp. 611-624.

Gorman, 2002a - B. K. Gorman, Birth weight and cognitive development in adolescence: causal relationship or social selection?. Social Biology, 49 (2002), pp. 419-435.

Gorman, 2002b • B. K. Gorman, Developmental well-being among low and normal birth weight U. S. Puerto Rican children. Journal of Health and Social Behavior, 43 (2002), pp. 419-435.

Goosby and Cheadle, 2009 • B. J. Goosby and J. E. Cheadle, Birth weight, math, and reading achievement growth: a multilevel between-sibling, between-families approach. Social Forces, 31 (2009), pp. 1291-1320.

Gottfried et al., 2003 - A. W. Gottfried, A. E. Gottfried, K. Bathurst, D. W. Guerin, and M. M. Parramore, Socioeconomic status in children's development and family environment: Infancy through adolescence, in M. H. Bornstein and R. H. Bradley, editors, Socioeconomic Status, Parenting, and Child Development, Lawrence Erlbaum Associates, Mahwa, NJ (2003).

Gortmaker and Wise, 1997 • S. L. Gortmaker and P. H. Wise, The first injustice: socioeconomic disparities, health services technology, and infant mortality. Annual Review of Sociology, 23 (1997), pp. 147-170.

Guo and Harris, 2000 - G. Guo and K. M. Harris, The mechanisms mediating the effects of poverty on children's intellectual development. Demography, 37 (2000), pp. 431-477.

Guo and VanWey, 1999 - G. Guo and L. K. VanWey, Sibship size and intellectual development: is the relationship causal?. American Sociological Review, 64 (1999), pp. 169-187.

Haas and Fosse, 2008 • S. A. Haas and N. Edward Fosse, Health and the educational attainment of adolescents: evidence from the NLSY97. Journal of Health and Social Behavior, 49 (2008), pp. 178-192.

Hack et al., 1995 - M. Hack, Nancy K. Klein and H. Gerry Taylor, Long-term developmental outcomes of low birth weight infants. The Future of Children, 51 (1995), pp. 176-196.

Hack et al., 2002 - M. Hack, D. J. Flannery, M. Schluchter, L. Cartar, E. Borawski and N. Klein, Outcomes in young adulthood for very-lowbirth-weight infants. The New England Journal of Medicine, 346 (2002), pp. 149-157.

Hahn et al., 1995 - R. A. Hahn, E. Eaker, N. D. Banker, S. M. Teusch, W. Sasniak and N. Krieger, Poverty and death in the United States - 19731991. Epidemiology, 6 (1995), pp. 490-497.

Hayward and Gorman, 2004 - M. D. Hayward and B. K. Gorman, The long arm of childhood: the influence of early-life social conditions on men's mortality. Demography, 411 (2004), pp. 87-107.

Hayward et al., 2000 - M. D. Hayward, T. P. Miles, E. M. Crimmins and Y. Yang, The significance of socioeconomic status in explaining the racial gap in chronic health conditions. American Sociological Review, 656 (2000), pp. 910-930.

Hillemeier et al., 2009 • M. M. Hillemeier, G. Farkas, P. L. Morgan, M. A. Martin and S. A. Maczuga, Disparities in the prevalence of cognitive delay: how early do they appear?. Paediatric and Perinatal Epidemiology, 23 (2009), pp. 186-198.

Horbar and Lucey, 1995 - J. D. Horbar and J. F. Lucey, Evaluation of neonatal intensive care technologies. The Future of Children, 5 (1995), pp. 139-161.

Hoyert et al., 2006 - D. L. Hoyert, T. J. Mathews, Fay Menacker, Donna M. Strobino and Bernard Guyer, Annual summary of vital statistics. Pediatrics, 1171 (2006), pp. 168-183.

Hughes and Simpson, 1995 - D. Hughes and L. Simpson, The role of social change in preventing low birth weight. The Future of Children, 5 (1995), pp. 87-102.

Kaestner and Lee, 2003 - R. Kaestner and W. C. Lee, The effects of welfare reform on prenatal care and birth weight. National Bureau of Economic Research Working Paper Series, Working Paper \#9769 (2003).

Kiel et al., 2007 - D. W. Kiel, E. A. Dodson, R. Artal, T. K. Boehmer and T. L. Leet, Gestational weight gain and pregnancy outcomes in obese women: How much is enough? Obstetric Gynecology, 1104 (2007), pp. 752-758.

Klebanov et al., 1994a • P. K. Klebanov, J. Brooks-Gunn, and M. C. McCormick, Classroom behavior of very low birth weight elementary school children. Pediatrics, 945 (1994), pp. 700-708.

Klebanov et al., 1994b - P. K. Klebanov, J. Brooks-Gunn, and M. C. McCormick, School achievement and failure in very low birthweight children. Developmental and Behavioral Pediatrics, 154 (1994), pp. 248-256.

Kline, 1998 - Rex B. Kline, Principles and Practice of Structural Equation Modeling, Guilford Press, New York (1998).

Lareau, 2003 - A. Lareau, Unequal Childhoods: Class, Race, and Family Life, University of California Press, Berkley and Los Angeles, CA (2003).

Lee and Burkham, 2002 - V. Lee and D. Burkham, Inequality at the starting gate: Social background difference in achievement as children begin school, Economic Policy Institute, Washington, DC (2002).

Little and Rubin, 2002 • Roderick J. A. Little and Donald B. Rubin, Statistical Analysis with Missing Data, Wiley, Hoboken, NJ (2002).

Lin et al., 2007 - M. -J. Lin, J. -T. Liu, and S. -Y. Chou, As low birth weight babies grow, can well-educated parents buffer this adverse factor? A research note. Demography, 44 (2007), pp. 335-343.

Link and Phelan, 1995 - B. G. Link and J. Phelan, Social conditions as a fundamental cause of disease. Journal of Health and Social Behavior, 35 (1995), pp. 80-94.

Long, 1997 • J. S. Long, Regression Models for Categorical and Limited Dependent Variables, Sage Publications, Thousand Oaks (1997).

Mayer, 1997 - Susan E. Mayer, What money can't buy: Family income and children's life chances, Harvard University Press, Cambridge, MA (1997).

McCormick et al., 1990 - M. McCormick, S. L. Gortmaker, and A. M. Sobol, Very low birth weight children: Behavior problems and school difficulty in a national sample. The Journal of Pediatrics, 1175 (1990), pp. 687-693.

McCormick et al., 1992 - M. C. McCormick, Jeanne Brooks-Gunn, Kathryn Workman-Daniels, JoAnna Turner, and George J. Peckham, The health and developmental status of very low birth weight children at school age. Journal of the American Medical Association, 26716 (1992), pp. 2204-2208.

McLoyd, 1998 • V. C. McLoyd, Socioeconomic disadvantage and child development. American Psychologist, 53 (1998), pp. 185-204.

Morgan et al., 2009 • P. L. Morgan, G. Farkas, M. M. Hillemeier, and S. Maczuga, Risk factors for learning-related behavior problems at 24 months of age: Population-based estimates. Journal of Abnormal Child Psychology, 37 (2009), pp. 401-413.

Muthén, 1994 • B. O. Muthén, Multilevel covariance structure analysis. Sociological Methods and Research, 22 (1994), pp. $376-398$.

Muthén, 1997 • B. O. Muthén, Latent variable modeling of longitudinal and multilevel data. Sociological Methodology, 27 (1997), pp. 453-480.

Paneth, 1995 • N. S. Paneth, The problem of low birth weight. The Future of Children, 51 (1995), pp. 19-34

Pappas et al., 1993 - G. Pappas, S. Queen, W. Hadden, and G. Fisher, The increasing disparity in mortality between socioeconomic groups in the United States 1960 and 1986. New England Journal of Medicine, 329 (1993), pp. 103-109.

Pearl et al., 2001 - M. Pearl, P. Braveman, and B. Abrams, The relationship of neighborhood socioeconomic characteristics to birthweight among 5 ethnic groups in California. American Journal of Public Health, 91 (2001), pp. 1808-1814. 
Raudenbush and Bryk, 2002 - Steve W. Raudenbush and Anthony S. Bryk, Hierarchical Linear Models: Applications and Data Analysis Methods, Sage Publications, Thousand Oaks (2002).

Reichman, 2005 • N. E. Reichman, Low birth weight and school readiness. Future of Children, 151 (2005), pp. 91-115.

Repetti et al., 2002 - R. L. Repetti, S. E. Taylor, and T. E. Seeman, Risky families: family social environments and the mental and physical health of offspring. Psychological Bulletin, 128 (2002), pp. 330-366.

Research, 2000 - Research, C. f. H. R., 2000. NLSY79 1998 Child and Young Adult Data Users Guide. The Ohio State University, Columbus. .

Royer, $2006 \cdot \mathrm{H}$. Royer, Separated at girth: US twin estimates of long run and intergenerational effects of fetal nutrients. Robert Wood Johnson Scholars in Health Policy Program Working Papers, WP-33 (2006).

Royston, 1991 - P. Royston, gr6: Lowess smoothing. Stata Technical Bulletin 3 (1991), 7-9. (Reprinted in Stata Technical Bulletin Reprints, vol. 1. Stata Press, College Station, TX, pp. 41-44).

Royston, 2004 • Patrick Royston, Multiple imputation of missing values. Stata Journal, 43 (2004), pp. 227-241.

Royston, 2005a • Patrick Royston, Multiple imputation of missing values: update. Stata Journal, 5 (2005), pp. 188-201.

Royston, 2005b • Patrick Royston, Multiple imputation of missing values: update of ice. Stata Journal, 5 (2005), pp. 527-536.

Sastry and Hussey, 2003 - N. Sastry and M. H. Hussey, An investigation of racial and ethnic disparities in birth weight in Chicago neighborhoods. Demography, 404 (2003), pp. 701-726.

Schafer, 1997 J. L. Schafer, Analysis of Incomplete Multivariate Data, Chapman \& Hall/CRC, Florida (1997).

Smith et al., 1997 - J. Smith, J. Brooks-Gunn, and P. Klebanov, Consequences of living in poverty for young children's cognitive and verbal ability and early school achievement, in G. J. Duncan and J. Brooks-Gunn, editors, Consequences of Growing Up Poor, Russell Sage, New York (1997), pp. 132-189.

Springer, 2009 - K. W. Springer, Childhood physical abuse and midlife physical health: testing a multi-pathway life course model. Social Science and Medicine, 69 (2009), pp. 138-146.

Strully and Conley, $2004 \cdot$ K. W. Strully and D. Conley, Reconsidering risk: adapting policies to intergenerational determinants and biosocial interactions in health related needs. Journal of Health Policy, Politics, and Law, 29 (2004), pp. 1073-1107. 